\title{
THERMAL ANALYSIS OF GLASS-FIBER REINFORCED POLYMER REBARS
}

\author{
Zarina SAIDOVA, Valery GRAKHOV, Grigory YAKOVLEV, \\ Anastasiya GORDINA, Andrey ZAKHAROV \\ Kalashnikov Izhevsk State Technical University, Studencheskaya Str. 7, \\ 426069 Izhevsk, Russian Federation
}

Received 24 August 2017; accepted 15 September 2017

\begin{abstract}
The article contains a short overview of current research base state in the field of thermal analysis of glass-fiber reinforced polymer (GFRP). The relationship between temperature raise and specimens weight loss is presented. It is noted that results of experiments run by different scientists vary widely and cannot form a common GFRP behavior model under heating. To compare the effect of thermal exposure on GFRP of a number of Russian manufacturers, the thermal analysis of composite rebar was carried out. Weight fluctuation was recorded with temperature ranging from 22 to $500^{\circ} \mathrm{C}$. The results of visual estimation of the effect of heating GFRP specimen up to $200{ }^{\circ} \mathrm{C}$ is also presented. All experiments were conducted according to requirements of corresponding regulations.
\end{abstract}

Keywords: thermal analysis, composite rebar, glass-fiber reinforced polymer, thermogravimetry, destruction temperature, conversion degree.

\section{Introduction}

Nowadays the application of composite materials as structural elements of buildings and constructions is gaining popularity worldwide due to their unique physical and mechanical properties, and, particularly, high corrosion resistance. However, their use in building structures, among other characteristics, requires compliance with standards for thermal stability.

Thermal stability, i.e. the ability to maintain constant chemical structure under changing environmental conditions, for example under exposure to high temperatures, plays an important role in material consideration. Methods that are most commonly used to evaluate the thermal stability of composites include: differential-thermal analysis, differential-scanning calorimetry, thermogravimetric analysis, and thermomechanical analysis. It is considered that the most descriptive one is the thermogravimetric analysis (or
TGA), which reflects the correlation between weight loss of the samples and the temperature change. Besides, the TGA can be used to calculate glass fiber and moisture contents, and to control the quality of the manufacturing process (Ershova et al. 2015).

The decrease in the mass of samples under the influence of high temperatures occurs primarily due to the degradation of the polymer matrix (Yang, Thomason 2013; Alsayed et al. 2012). As is known from Tjukaev (1974), composite materials with polyester resins can be operated up to $60 \ldots 150{ }^{\circ} \mathrm{C}$, epoxies up to $80 \ldots 200{ }^{\circ} \mathrm{C}$, phenol-formaldehyde up to $150 \ldots 250^{\circ} \mathrm{C}$, polymides up to $200 . . .400{ }^{\circ} \mathrm{C}$. Experimental data (Kudryashov et al. 2015a, 2015b) suggest that irreversible changes in composites occur at temperatures above $300{ }^{\circ} \mathrm{C}$, which appears to be critical for GFRP. Thus, the use of glass fiber reinforced polymers is limited due to the rapid loss of its physical and mechanical properties during heating. 
Today most tests on composite materials are carried out on composite reinforcement. Experimental data (Golovanov et al. 2013) indicate that during intensive heating of the working reinforcement up to $100^{\circ} \mathrm{C}$, an active release of vapor from the adjacent microcracks in concrete occurs. This instantly increases the pressure on the surface of the reinforcement leading to fiber destruction (Shirko et al. 2015; Gutnikov 2010).

Thought it is important to understand that under laboratory conditions the destruction of composites runs faster than in reality, as polymers interact with the oxygen of the air, which is excluded under service conditions of working in concrete (Tanano et al. 1995). Besides, concrete has low thermal conductivity and subsequently acts as insulation for the reinforcement, preserving the temperatures at the rebar level within a low range and thus allowing for an adequate strength during the thermal exposure (Blontrock et al. 1998).

In order to gain a deeper insight into the structural behavior of such new materials and to guarantee their safe application, many researches have been carried out in specific areas that concern the structural performance and durability under service conditions.

Gibson et al. (Galati et al. 2004; Sayed-Ahmed, Shrive 1999) ran TGA on vinyl ester, polyester and phenolic resins, and reported very comparable curves for the polyester and vinyl ester resin, characterized by the start of the decomposition process at about $350^{\circ} \mathrm{C}$; leaving only about $7 \%$ of the material as char by the time the temperature had reached $480{ }^{\circ} \mathrm{C}$.

Eedson (2013) run tests on materials in accordance with ASTM E2550 (ASTM 2007) using a TA Instruments TGA Q500 thermogravimetric analyzer (ASTM E2550:2007). Samples were placed on a platinum dishes and heated with a rate of $10{ }^{\circ} \mathrm{C}$ per minute from $20{ }^{\circ} \mathrm{C}$ to $600{ }^{\circ} \mathrm{C}$ in a nitrogen atmosphere. The tests were carried out on samples of composite material with different fibers and on epoxy resin samples. The attempt to test the reinforcing fibers separately failed because of their low weight, which made it extremely difficult to fix them on a platinum dish throughout experiment.

The results of the study (Eedson 2013) showed that there was no significant mass loss until well above $200{ }^{\circ} \mathrm{C}$. At a temperature of $300^{\circ} \mathrm{C}$, the weight loss was approximately $2 \%$. At a temperature of $365^{\circ} \mathrm{C}$, a sample of a heat-resistant epoxy resin (type S-T) lost more than $50 \%$ of its mass, so its decomposition temperature lies between 345 and $385{ }^{\circ} \mathrm{C}$. Strangely enough, the temperature of destruction of an ordinary epoxy resin sample (type S) was higher and lies in the range 378$405{ }^{\circ} \mathrm{C}$. The loss of mass of composite samples (with glass fiber filler) had the same pattern, and at a temperature of $600{ }^{\circ} \mathrm{C}$ it decreased almost two times. The TGA data are shown in Figure 1 (Eedson 2013).

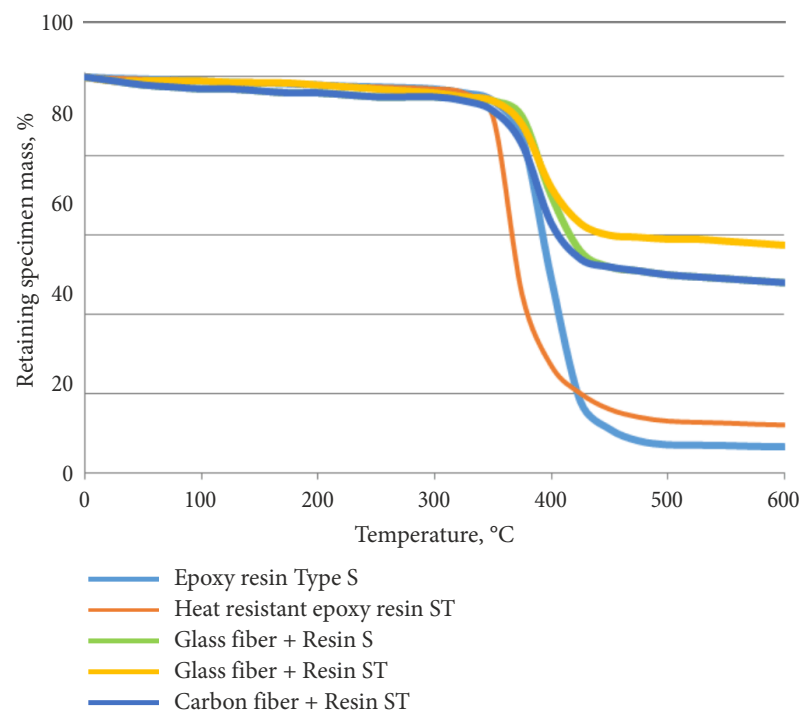

Fig. 1. TGA of epoxy resin samples type S and ST and composite materials

Robert, Benmokrane (2010) run TGA tests on GFRP bars produced by Pultrall Inc. The weight loss of a sand coated sample was recorded during the temperature rise from 20 to $800{ }^{\circ} \mathrm{C}$. The tests were carried out in accordance with ASTM E1868:2004 on the TA Instruments TGA Q500 installation. Two important drops took place: the first, quite insignificant, occurred at a temperature of $150{ }^{\circ} \mathrm{C}$, the second began at $300{ }^{\circ} \mathrm{C}$ and continued to $450{ }^{\circ} \mathrm{C}$, comprising a roughly $18 \%$ total mass loss.

Alsalihi (2014) carried out TGA tests on small GFRP bars $(22.13 \mathrm{mg})$ in order to evaluate the correlation between sample weight loss and temperature increase (up to $800{ }^{\circ} \mathrm{C}$ ). On the weight loss and temperature curve several sample mass drops are noted. First drop was at about $90^{\circ} \mathrm{C}$, and the second occurred at about $270{ }^{\circ} \mathrm{C}$. The third commenced at $350{ }^{\circ} \mathrm{C}$ and continued up to $400{ }^{\circ} \mathrm{C}$. The total weight loss reached $25 \%$. Noted that, first two cases were associated with the release of moisture from the composite, namely, from reinforcing fibers. The third and subsequent cases were related to the degradation of the vinyl ester resin matrix. 
Costa Pires (2012) completed the thermogravimetric analysis on TA Instruments in accordance with ISO 11357 standard (ISO 11357-4:2014). Tests were carried out on small rectangular samples weighing about $10 \mathrm{mg}$ cut from flat profiles of glass-fiber profiles produced by Fiberline DK. Samples were heated from room temperature to $600{ }^{\circ} \mathrm{C}$ at a fixed rate of $5,10,15$ and $20{ }^{\circ} \mathrm{C}$ per minute, in air and nitrogen atmospheres. During the test, the correlation between the mass change and the temperature effect duration and intensity was recorded.

As a result, it was found that at a heating rate of $5{ }^{\circ} \mathrm{C}$ per minute the polymer degradation temperature was $350{ }^{\circ} \mathrm{C}$. The sample weight reduced to $87.5 \%$ of its original. Figure 2 shows the mass - temperature curves of the GFRP (Costa Pires 2012).

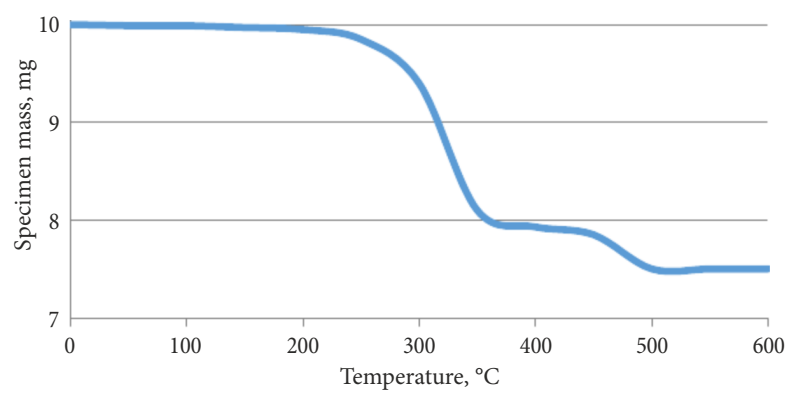

Fig. 2. The mass change of the GFRP while heating at the rate of $5^{\circ} \mathrm{C}$ per minute

After the fire test conducted by Dezfouli (2003), samples of the rebars were collected from the tension face in the mid-centre of the beam in order to evaluate the effect of fire on the rebars. The samples were weighed and compared with unexposed samples. The weight of the rebar produced by Hughes Brothers, Inc. (No. 1) and Dow Chemical Company (No. 2) decreased by $22.3 \%$ and $33.8 \%$, respectively, strength characteristics deteriorated as well (Dezfouli 2003).

Thus, the thermo-mechanical characteristics of GRP samples obtained during the tests in the abovementioned sources differ significantly. The curves of the dependence of mass reduction on temperature have a different character and severity, for example, a decrease in the mass of the sample at $400{ }^{\circ} \mathrm{C}$ varies from 20 to $50 \%$. The reason for this may be the difference in the chemical composition of the material, the discrepancy between the test conditions of the samples, such as the speed and duration of heating, the mass of the samples and their shape, the type of testing apparatus and the mechanism of recording the results. To exclude the influence of these factors and to assess the thermo-mechanical characteristics of the material more adequately, it is important to maintain same conditions when testing composites of a similar chemical nature.

\section{Materials and methods}

In order to compare the behavior of the FRP rebars of similar chemical composition at elevated temperatures, the samples of composite rebars of the following manufacturers were tested: No. 1 - KomAR, No. 2 Athena (Arplastic), No. 3 - Tekhcom, No. 4 - Armastek, No. 5 - Volgastal Composite.

The structure of all FRP rods includes glass roving, bonded with epoxy resin polymer. The epoxy binder of "KomAR" GFRP is strengthened with a modifying additive, more specifically, metal/carbon nanocomposite. Epoxy binder in this composition is a carbonaceous polymer, which in the temperature range up to $500{ }^{\circ} \mathrm{C}$ leads to carbonization process, and additives like metal/carbon nanocomposite accelerate this effect.

The studies of thermal effects on GFRP rods were carried out on the Shimadzu DTG-60H derivatograph. The heating rate was $5{ }^{\circ} \mathrm{C}$ per minute, the maximum temperature reached $500{ }^{\circ} \mathrm{C}$. In the course of the study, the curves for the change in mass and the thermal effects produced by thermal exposure on fiberglass rod elements were plotted.

Visual assessment of the samples subjected to the temperature effect was carried out according to GOST 29127-91 (ISO 7111-87) on the fiberglass reinforcing rods produced by following manufacturers:

\section{No. 1 - KomAR, \\ No. 2 - Armastek, \\ No. 3 - Strongroup, \\ No. 4 - Arplastic.}

The main characteristics of all GFRP rods are their tensile strength $[\mathrm{MPa}]$ and tensile modulus [GPa]. For the above mentioned specimens they were respectively: No. 1 - $1250 \mathrm{MPa} / 55 \mathrm{GPa}$; No. 2 $1000 \mathrm{MPa} / 50 \mathrm{GPa}$; No. 3 - $1350 \mathrm{MPa} / 62 \mathrm{GPa}$; No. 4 $1120 \mathrm{MPa} / 51 \mathrm{GPa}$. The required values, according to Russian national code (GOST 31938-2012), are not less than $800 \mathrm{MPa}$ and not less than $50 \mathrm{GPa}$ respectively.

The samples were heated in a muffle furnace at a rate of $30{ }^{\circ} \mathrm{C}$ per minute in the laboratory of Research Institute Stroilab in Izhevsk. The changes were recorded at the following control points: $20,80,100$, $150,180,200,220,260,300^{\circ} \mathrm{C}$. 


\section{Results and discussion}

Table 1 shows the results of a study conducted on the Shimadzu DTG-60H derivatograph in terms of changing the mass of various rod elements at a heating rate of $5{ }^{\circ} \mathrm{C}$ per minute, a minimum temperature of $22{ }^{\circ} \mathrm{C}$, and a maximum temperature of $500{ }^{\circ} \mathrm{C}$.

Table 1. Relative weight loss, $\%$

\begin{tabular}{|c|c|c|c|c|c|}
\hline \multirow{2}{*}{$\begin{array}{c}\text { Temperature, } \\
{ }^{\circ} \mathrm{C}\end{array}$} & \multicolumn{5}{|c|}{$\Delta, \%$ for a sample number } \\
\cline { 2 - 6 } & 1 & 2 & 3 & 4 & 5 \\
\hline 100 & 0.12 & 0.42 & 0.43 & 0.12 & 0.27 \\
\hline 200 & 0.42 & 0.61 & 0.34 & 0.35 & 0.69 \\
\hline 300 & 2.38 & 3.68 & 2.73 & 2.82 & 3.79 \\
\hline 400 & 10.34 & 19.62 & 13.97 & 16.05 & 20.96 \\
\hline 500 & 7.28 & 14.51 & 8.85 & 10.88 & 14.83 \\
\hline
\end{tabular}

In the course of the study, the curves of the mass change of fiberglass rod elements and the thermal effects under thermal exposure were plotted.

Figure 3 shows the results of the mass change for various rod elements under thermal exposure.

Two main zones were identified on the TG curves: the first $\left(\mathrm{Ti}=260^{\circ} \mathrm{C}\right)$ corresponded to the beginning of the mass loss and coincided with a significant increase in the exothermic effect. The second zone $(\mathrm{Ti}=$ $360{ }^{\circ} \mathrm{C}$ ) recorded a decrease in mass and exothermic effect (Fig. 3).

The mass loss of the rod elements under thermal exposure varied from 19 to $36 \%$. The speed of the fracture process and the heat resistance of five rod elements also varied widely. Noted that, sample No. 1 had the lowest mass loss rate and the highest stability under thermal exposure. At the temperature of $370{ }^{\circ} \mathrm{C}$, the mass of samples 1 and 3 stabilized, and in the range from 400 to $500{ }^{\circ} \mathrm{C}$ it slowed down, in contrast to samples 2, 4 and 5 . The minimum value of the mass loss corresponds to the rod element at No. 1,

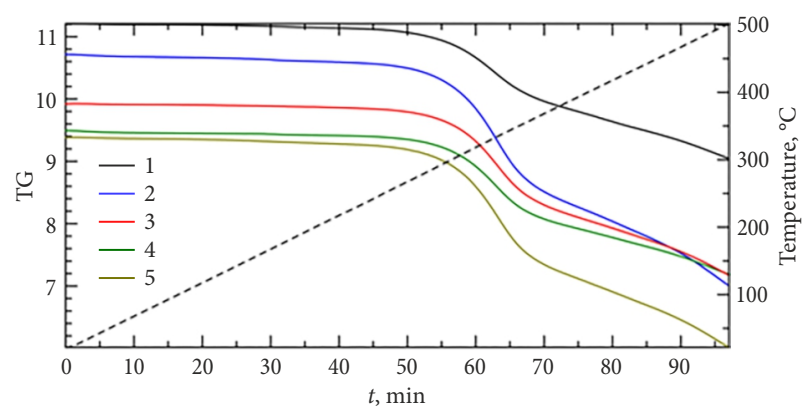

Fig. 3. TG curves for GFRP rod elements it is almost two times less than that of the samples of other manufacturers. At the same time, the destruction temperature of sample No. 1 is higher than the other samples studied at $80{ }^{\circ} \mathrm{C}$ (increased from $180{ }^{\circ} \mathrm{C}$ to $260^{\circ} \mathrm{C}$ ). Thus, the rate of destruction process decreases and the heat resistance rises in the series: 2 sample -5 sample - 4 sample - 3 sample - 1 sample.

The study shows that the nature of the destruction of the sample No. 1 was slightly different from the other samples, the DTA curve had one broad exothermic peak having several inflection points, i.e. consisting of several exothermic processes (Fig. 5). Apparently, stepwise oxidation occurs, accompanied by the beginning of carbonization processes, which reduces the rate of mass change and slows down the oxidation of the epoxy binder. In other samples, the exothermic peak was flat and drifted to a second one, with lower intensity.

The nature of failure for all elements is the softening and oxidation processes under thermal exposure. The structure of fiberglass reinforcement includes glass fiber, bonded with a polymer based on epoxy resin. The composition of the epoxy binder of the company "KomAR" includes a modifying additive including a metal/carbon nanocomposite.

Table 2 presents the results of calculating the dependence of the conversion degree on the temperature for various types of rod elements. Control points correspond to temperatures of $100{ }^{\circ} \mathrm{C}, 200{ }^{\circ} \mathrm{C}, 300{ }^{\circ} \mathrm{C}$, $400{ }^{\circ} \mathrm{C}$. The conversion degree was calculated using the formula 1 :

$$
\alpha=\Delta \mathrm{m}_{\mathrm{i}} / \Delta \mathrm{m}_{\max },
$$

where $\Delta \mathrm{m}_{\mathrm{i}}$ and $\Delta \mathrm{m}_{\max }$ - current and maximum value of the mass change, respectively.

The values of the conversion degree at the selected control points are similar for all rod elements. It was noted that samples 1,4 and 5 at the control point of $100{ }^{\circ} \mathrm{C}$ have a conversion value lower than those No. 2 and 3 .

Table 2. Calculation of the conversion degree of different GFRP rod elements

\begin{tabular}{|c|c|c|c|c|c|}
\hline \multirow{2}{*}{$\begin{array}{c}\text { Temperature, } \\
{ }^{\circ} \mathrm{C}\end{array}$} & \multicolumn{5}{|c|}{ Conversion degree $\alpha$ for specimen number } \\
\cline { 2 - 6 } & 1 & 2 & 3 & 4 & 5 \\
\hline 100 & 0.006 & 0.012 & 0.018 & 0.004 & 0.007 \\
\hline 200 & 0.028 & 0.030 & 0.032 & 0.017 & 0.027 \\
\hline 300 & 0.150 & 0.140 & 0.140 & 0.119 & 0.131 \\
\hline 400 & 0.670 & 0.680 & 0.700 & 0.680 & 0.690 \\
\hline
\end{tabular}


Figure 4 shows the DTG curves for the investigated samples of GRP.

Figure 5 illustrated the DTA curves for experimental GFRP samples.

Visual assessment of samples of fiberglass reinforcement bars of the following manufacturers: No. 1 KomAR, No. 2 - Armastek, No. 3 - Strongrupp, No. 4 - Arplastic, exposed to high temperature in a muffle furnace at a heating rate of $30^{\circ} \mathrm{C}$ per minute in the temperature range from 20 to $300^{\circ} \mathrm{C}$ indicates that at a temperature of $300{ }^{\circ} \mathrm{C}$ (Fig. 6):

- specimen No. 2 had cracks at the surface of the power rod,

- the surface of specimen No.3 was significantly coked, which lead to cracks formation between the winding thread and the power rod,

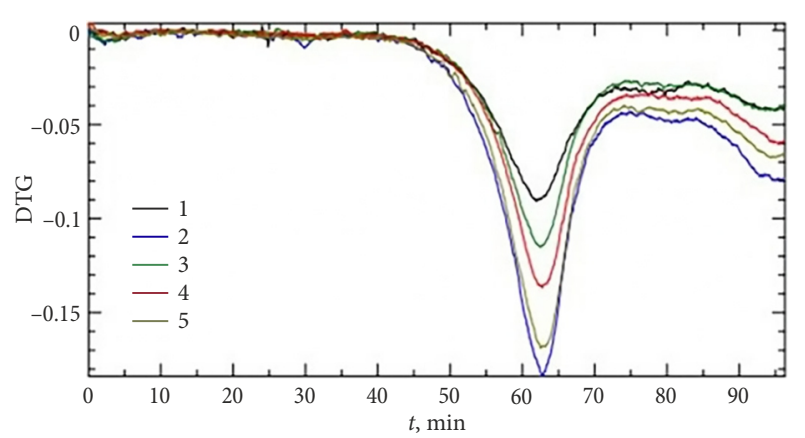

Fig. 4. DTG curves for GFRP rod elements

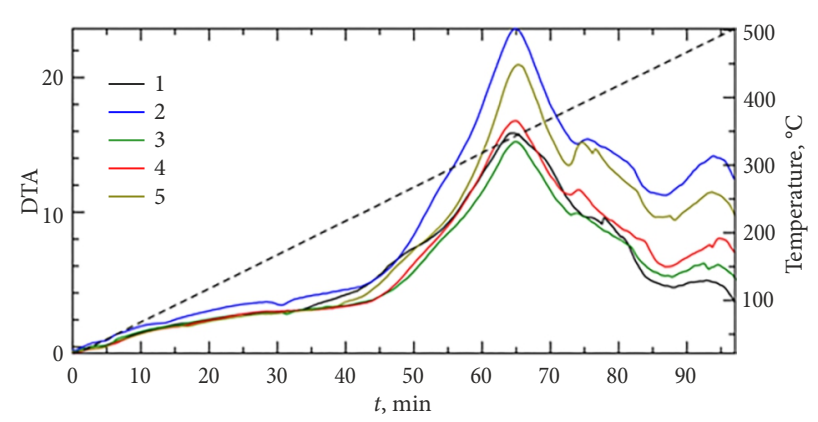

Fig. 5. DTA curves of rod GFRP elements

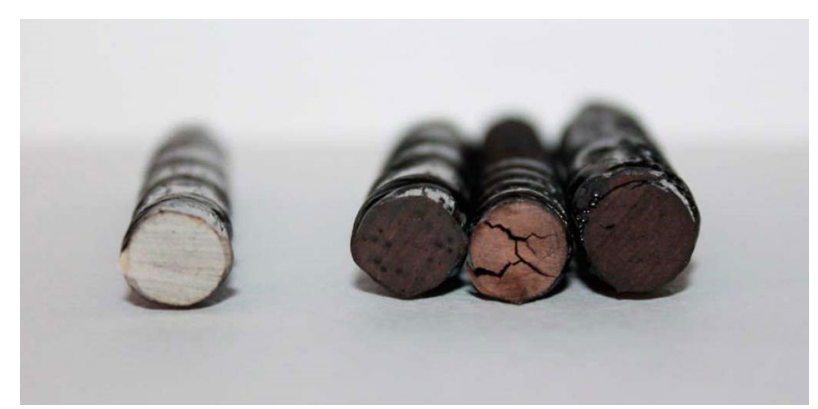

Fig. 6. Cross-section of specimens after exposure to high temperature $\left(300^{\circ} \mathrm{C}\right)$ for 30 minutes
- at the cross section of specimen No. 4 there were large cavities, which most probably indicate the localization of impregnating binder clots in the structure of the power rod.

Sample No. 1 had the minimum possible weight loss (1.5\%) at a temperature of $300{ }^{\circ} \mathrm{C}$ and no surface defects, while the mass loss of samples No. 1, 2, 3 at $300{ }^{\circ} \mathrm{C}$ exceeded 5\%, which made it impossible to use them under given temperature conditions.

The consequences of the temperature exposure on the GFRP samples of different manufacturers are shown in Figure 6.

Based on these tests, the dependence of mass loss of samples on temperature was also derived. The results are presented in Table 3. The recorded mass decrease of the samples reached $16 \%$ in some cases even when heated to $200{ }^{\circ} \mathrm{C}$.

Table 3. Mass reduction of samples, $\%$

\begin{tabular}{|c|c|c|c|c|}
\hline \multirow{2}{*}{ Temperature, ${ }^{\circ} \mathrm{C}$} & \multicolumn{4}{|c|}{$\Delta(\%)$ for the sample No } \\
\cline { 2 - 5 } & 1 & 2 & 3 & 4 \\
\hline 100 & 0.05 & 5.5 & 6.3 & 1.5 \\
\hline 200 & 1.5 & 15.1 & 16.3 & 6.3 \\
\hline
\end{tabular}

\section{Conclusions}

Thus, the results of these tests show that GFRP rods can differ significantly in terms of thermomechanical characteristics even when tested under the same conditions.

The weight loss of the rod elements under thermal exposure varied from 19 to $36 \%$. The speed of the fracture process and the heat resistance of five rod elements also varied widely. Noted that, sample of "KomAR" ltd. had the lowest mass loss rate and the highest stability under thermal exposure.

Visual assessment of samples of fiberglass reinforcement bars showed that after exposure to high temperature some specimen had cracks at the surface of the power rod; the surface of other specimen was significantly coked, leading to cracks formation between the winding thread and the power rod. At the cross section of another specimen there were large cavities, which most probably indicate the presence of impregnating binder clots in the structure of the power rod. Only one rod element remained unchanged during this experimental study.

Obviously, this is due to the diversity of chemical structures of specimens, and the differences of quality control methods used by manufacturers during 
the development and production cycles, which once again confirms the need for proper certification and standardization of materials. The issue of changing physical and mechanical properties of GFRP under exposure to high temperatures requires more profound analysis and will undoubtedly become the subject of further research.

\section{References}

Alsalihi, M. A. J. 2014. Mechanical properties of glass fiber reinforced polymer bars after exposure to elevated temperatures: MSc dissertation. Wisconsin University, Milwaukee.

Alsayed, S.; Al-Salloum, Y.; Almusallam, T.; El-Gamal, S. 2012. Performance of GFRP bars under elevated temperatures, Composites Part B: Engineering 2012: 2265-2271.

https://doi.org/10.1016/j.compositesb.2012.01.034

ASTM E1868. Standard test methods for loss-on-drying by thermogravimetry. ASTM, 2004.

ASTM E2550. Standard test method for thermal stability by thermogravimetry. ASTM, 2007.

Blontrock, H.; Taerwe, L.; Matthys, S. 1998. Properties of fibre reinforced plastics at elevated temperatures with regard to fire resistance of reinforced concrete members, Fibre Reinforced Polymer Reinforcement, 43-54.

Costa Pires, J. M. 2012. Mechanical behaviour at elevated temperatures of GFRP pultruded composite profiles: MSc dissertation. Técnico Lisboa.

Dezfouli, A. A. 2003. Behaviour of GFRP rebars reinforced concrete elements under elevated temperature and fire: $\mathrm{PhD}$ dissertation. Material Dept., Queen Mary University, London.

Eedson, R. T. 2013. The effects of elevated temperatures on fibre reinforced polymers for strengthening concrete structures: MSc thesis. Civil Engineering Dept., Queen's University, Kingston, Ontario, Canada.

Ershova, O. V.; Melnichenko, M. A.; Trifonova, K. V. 2015. The use of the differential scanning calorimetry and thermogravimetric analysis for determining the composition and degradation temperature of secondary polymers, Achievements of Contemporary Science 11(part 1): 26-30.

Galati, N.; Vollintine, B.; Nanni, A.; Dharani, L. R.; Aiello, M. A. 2004. Thermal effects on bond between FRP rebars and concrete, Advanced Polymer Composites for Structural Applications in Construction: ACIC 2004. Elsevier Inc., 501-508.
Golovanov, V. I.; Pavlov, V. V.; Pekhotnikov, A. V. 2013. Experimental and analytical research of fire resistance solid concrete slab with steel and composite reinforcement, Fire Safety 2: 44-51.

GOST 29127-91 (ISO 7111-87). Plastics. Thermogravimetry of polymers. Temperature scanning method. IPK Standards Publishing House, Moskva, 1993. 5 p.

GOST 31938-2012. Fibre-reinforced polymer bar for concrete reinforcement. General specifications. Standartinform, Moskva. $34 \mathrm{p}$.

Gutnikov, S. I. 2010. Glass fibers. M.: Lomonosov Moscow State University. $53 \mathrm{p}$.

ISO 11357-4:2014. Plastics. Differential scanning calorimetry (DSC). Part 4: Determination of specific heat capacity. $12 \mathrm{p}$.

Kudryashov, V. A.; Drobysh, A. S.; Solovjanchik, A. M. $2015 \mathrm{a}$. Experimental research of fire-resistance of polymer composite structures with fireproofing, The Reporter of Command and Engineering Institute of the Ministry of Emergencies of the Republic of Belarus 1(21): 25-29.

Kudryashov, V. A.; Drobysh, A. S.; Solovjanchik, A. M. 2015b. The results of experimental researches of GFRP fire-resistance, The Reporter of Command and Engineering Institute of the Ministry of Emergencies of the Republic of Belarus 1(21): $17-24$.

Robert, M.; Benmokrane, B. 2010. Behavior of GFRP reinforcing bars subjected to extreme temperatures, Journal of Composites for Construction 14: 353-360. https://doi.org/10.1061/(ASCE)CC.1943-5614.0000092

Sayed-Ahmed, E. Y.; Shrive, N. G. 1999. Smart FRP prestressing tendons: properties and prospects, in A. H. Hosny, I. Mahfouz, S. Sarkani (Eds.). Proc., Second Middle East Symp. on Structural Composites for Infrastructure Applications, 80-93.

Shirko, A. V.; Kamluk, A. N.; Spiglazov, A. V.; Drobyhs, A. S. 2015. Evaluation of mechanical properties of composite rebar under temperature exposure, Mechanics of Machines, Mechanisms and Materials 2(31): 59-65.

Tanano, H.; Masuda, Y.; Kage, T.; Fukuyama, H. 1995. Fire resistance of continuous fibre reinforced concrete, Non-metallic (FRP) Reinforcement for Concrete Structures, 368-375.

Tjukaev, V. N. 1974. Constructional plastics. M.: Strojzdat. 135 p.

Yang, L.; Thomason, J. L. 2013. The thermal behavior of glass fiber investigated by thermomechanical analysis, Journal of Materials Science 48: 5768-5775. https://doi.org/10.1007/s10853-013-7369-7

Zarina SAIDOVA is the first year PhD student of "Construction materials and products" study course, Kalashnikov Izhevsk State Technical University. Research interests: the behavior of composite materials exposed to different types of loads.

Valery GRAKHOV. Doctor of Economic Sciences, Prof., Rector of Kalashnikov Izhevsk State Technical University. Author of more than 200 scientific articles. Field of study: current tendencies in structural composites application in construction industry.

Grigory YAKOVLEV. Doctor of Engineering Sciences, Prof., Head of the "Geotechnics and Construction Materials" department of Kalashnikov Izhevsk State Technical University. Author of more than 150 articles and scientific research papers. Field of study: research of the structure and properties of structural composites improved with different dispercity modifiers.

Anastasiya GORDINA. Candidate of Engineering Sciences, Assoc. Prof. of the "Geotechnics and Construction Materials" Department. Field of study: modern methods of physical and chemical analysis of structural composites.

Andrey ZAKHAROV. Chief manufacturing engineer of "KomAR" tld. Research interests: modern construction materials modified with metal/carbon nanostructures, application of glass fiber reinforced polymers in construction industry. 